\title{
PELANGGARAN MAKSIM PRINSIP KERJA SAMA TOKOH UTAMA PADA FILM 梁祝(LIANG ZHU) SAMPEK ENGTAY
}

Galih Wibisono, B.A., M.Ed.

Jurusan Bahasa dan Sastra Mandarin Universitas Negeri Surabaya galih_li@yahoo.com

\begin{abstract}
Abstrak
Tulisan ini bertujuan mendeskripsikan pelanggaran terhadap maksim-maksim dalam Prinsip Kerja Sama Grice yang terdapat dalam film berbahasa Mandarin yaitu 梁祝 (Liang Zhu). Berdasarkan hasil analisis pada film tersebut ditemukan bahwa (1) pelanggaran maksimmaksim prinsip kerjasama berupa pelanggaran maksim kuantitas, pelanggaran maksim kualitas, pelanggaran maksim relevan, dan pelanggaran maksim cara. Terdapat akibat yang ditimbulkan terhadap keempat maksim dalam pertuturan tersebut. Tuturan yang melanggar maksim kuantitas mengakibatkan tidak informatifnya sebuah tuturan karena informasi yang diberikan terlalu berlebihan. Pelanggaran maksim kualitas dapat mengakibatkan lawan tutur salah menangkap informasi karena informasi yang disampaikan penutur tidak meyakinkan atau tidak benar. Kemudian, pelanggaran pada pelanggaran maksim relevan dapat menimbulkan ketidaksambungan pertuturan antara pihak penutur dan petutur. Terakhir, pelanggaran maksim cara dapat mengakibatkan salah paham dan kebingungan pada pihak penutur dan petutur karena ketidakjelasan makna tuturan dan (2) fungsi pelanggaran maksimmaksim prinsip kerjasama yaitu fungsi asertif dan fungsi ekspresif. Pelannggaran terhadap maksim-maksim tersebut berfungsi asertif memiliki maksud untuk menunjukkan, menjelaskan alasan. Selain itu, pelanggaran pada fungsi ekspresif yaitu berfungsi untuk menunjukkan perasaan jengkel dan keluhan.
\end{abstract}

Kata kunci: prinsif kerja sama, maksim dalam prinsip kerja sama, bentuk pelanggaran maksim, fungsi pelangaran maksim

\section{A. Pendahuluan}

Manusia merupakan mahluk sosial yang selalu berkomunikasi terhadap sesama manusia dan lingkungan sekitarnya. Salah satu alat komunikasi yang sering digunakan oleh manusia adalah dengan menggunakan bahasa. Menurut Tarigan (1993:4), fungsi bahasa adalah suatu kenyataan bahwa manusia mempergunakan bahasa sebagai sarana komunikasi vital dalam hidup ini.

Bahasa di dunia sangat beragam, karena masing-masing negara memiliki bahasa sendiri. Salah satu bahasa yang berasal dari negeri Tiongkok adalah bahasa Mandarin. Sebagaimana diketahui, bahasa Mandarin merupakan salah satu dari enam bahasa PBB yang paling penting dan sering digunakan dalam PBB (黄伯荣 dan 廖序东,2008:13). Hal ini membuktikan bahwa bahasa Mandarin juga memiliki peran penting penggunaanya di dunia internasional. 
Komunikasi dapat diwujudkan dalam sebuah percakapan yang melibatkan dua orang atau lebih untuk menyampaikan sebuah perasaan, ide, dan keinginan berupa tuturan atau ujaran. Dalam pertuturan, prinsip kerja sama (PK) dibutuhkan untuk lebih mudah menjelaskan hubungan antara makna dan daya, penjelasan yang demikian sangat memadai, khususnya untuk memecahkan masalah-masalah yang timbul dalam semantik yang memakai pendekatan berdasarkan kebenaran (truth-based approach) (Leech,1993:120). Perlu adanya sebuah kerja sama antara penutur dan lawan tutur agar pesan yang ingin disampaikan dapat di terima dengan baik. Akan tetapi, pihak penutur maupun petutur terkadang bahkan harus melakukan pelanggaran prinsip kerjasama dalam berkomunikasi. Hal tersebut dilakukan dengan maksud untuk tetap menjaga komunikasi yang terjalin dengan baik dan tidak menyinggung. Contoh pelanggaran prinsip kerjasama sering dijumpai pada dialog antartokoh di film Tiongkok.

Salah satu film berbahasa Mandarin yaitu 梁祝（Liang Zhu） atau Sampek Engtai. Film 梁祝 (Liang Zhu) merupakan film klasik Tiongkok yang sangat terkenal di Tiongkok maupun di Indonesia. Dalam pertuturan antartokoh pada film ini biasanya terdapat prinsip kerja sama. Penelitian ini menggunakan PK yang dirumuskan oleh Grice (dalam Leech,1993:11) untuk menganalisis pertuturan yang terdapat dalam film tersebut. Dalam PK terdapat 4 maksim, yakni: (1) maksim kuantitas, "Berikan jumlah informasi yang tepat", (2) maksim kualitas, "Usahakan agar sumbangan informasi Anda benar", (3) maksim hubungan, "Usahakan agar perkataan Anda ada relevansinya", dan (4) maksim cara, "Usahakan agar tuturan Anda mudah dimengerti”.

Penelitian ini memilih film berbahasa Mandarin 梁祝 ( Liang Zhu), karena 梁祝 (Liang Zhu) merupakan sebuah film roman klasik yang sangat terkenal di Tiongkok . Selain itu, kisah cinta yang disuguhkan pada film ini sangat bagus. Pada film ini diceritakan sebuah kisah cinta antara Liang Shan Bo dan Zhu Ying Tai yang sangat tragis. Film ini tidak hanya disukai oleh masyarakat Tiongkok, tetapi masyarakat Indonesia juga sangat menyukai kisah cinta pada film ini.

Berdasarkan hasil kegiatan prapenelitian dialog yang terjadi pada film 梁祝 (Liang Zhu) tersebut, telah banyak dijumpai pelanggaran maksim PK beserta fungsinya. Selain itu, masih kurangnya penelitian tentang pelanggaran maksim prinsip kerja samadan fungsinya dalam film roman klasik Tiongkok menjadikan penelitian ini menarik untuk dilakukan.

Makalah hasil penelitian pustaka ini juga merupakan penelitian deskriptif kualitatif. Data berupa kutipan tuturan tokoh dan antratokoh yang didalamnya terdapat pelanggaran PK dan 
dikumpulkan dengan teknik dokumentasi. Data tersebut dianalisis dengan teknik deskriptif interpretatif.

\section{B. Pembahasan}

\section{Pelanggaran Maksim Kuantitas dan Fungsinya}

Data berikut ini berkonteks Zhu Ying Tai mencari Liang Shan Bo. Dia menemukannya di sebuah perpustakaan yang gelap dan hanya diterangi dai cahaya lilin. Kemudian, Zhu Ying Tai terkejut karena ternyata terdapat sebuah tempat yang berisikan barang-barang Liang Shan Bo dan menanyakan apakah Shan Bo tinggal di perpustakaan.

\section{(1) Zhu Ying Tai：你睡在这儿呀?（Nǐ Shuì zài Zhè er ya?）}

Kamu tidur disini?

（2）Liang Shanbo: 是呀。我家是末落仕族。就靠我娘亲供我读书，幸得院仕 夫人格外通 情。誏我做䧻役来填补不是学费。我现在在这儿一边做事, 一边攻读。 Iya, Keluargaku mengalami kemerosotan. Ibu tentu sangat ingin mendukung pendidikanku. Untungnya, Kepala sekolah sangat murah hati. Membiarkanku bekerja di sini untuk membayar pendidikanku. Sekarang Aku sambil bekerja sambil belajar di sini.

(LZ.LSB.1.00:31:41-00 : $31: 54$ )

Dalam pertuturan tersebut terdapat pelanggaran PK. Dapat dijelaskan bahwa tuturan (2) telah melanggar salah satu maksim prinsip kerja sama yaitu maksim kuantitas. Pelanggaran yang dilakukan oleh Liang Shan Bo (2) yaitu “我家是末落仕族。就靠我娘亲供我读书， 幸得院仕夫人格外通情。誏我做维役来填补不是学费。我现在在这儿一边做事, 以便 攻读。” adalah tuturan yang lebih informatif dari yang diminta. Seharusnya Liang Shan Bo menuturkan (2) “是, 我睡在这儿” yang artinya $Y a$, Aku tidur di sini sudah cukup informatif untuk menjawab pertanyaan Zhu Ying Tai. Dengan demikian tuturan yang disampaikan Liang Shan Bo sudah cukup informatif dan tidak berlebihan, sehingga tuturan (2) memenuhi maksim kuantitas.

Dari tuturan “我家是末落仕族。就靠我娘亲供我读书，幸得院仕夫人格外通情。 誏我做䧻役来填补不是学费。我现在在这儿一边做事, 以便攻读。” yang dilakukan oleh Liang Shan Bo sebenarnya bermaksud menunjukkan kehidupan yang dialaminya. Saat ini, dia memilih untuk tinggal di perpustakaan sekolah sambil bekerja. Maka pelanggaran maksim kuantitas pada tuturan (2) memiliki fungsi asertif yaitu menunjukkan.

\section{Pelangaran Maksim Kualitas dan Fungsinya}


Data kedau berkonteks, Zhu Ying Tai sedang mencari Liang Shan Bo tetapi tidak berjumpa. Namun, di tengah perjalanan Dia bertemu sekelompok siswa yang juga teman Liang Shan Bo. Kemudian, Zhu Ying Tai menanyakan keberadaan Liang Shan Bo kepada mereka.

(3) Zhu Ying Tai : 请问, 你知不知道梁山伯在哪儿?

Permisi mau tanya, kamu tahu Shan Bo di mana?

(4)Teman Shabo : 谁是梁山伯? 不认识!

Siapa Shan Bo? Tidak kenal !

(LZ.TSB.2.00:31:06-00:31:11 )

Pada pertuturan tersebut, teman Liang Shan Bo (4) telah melakukan pelanggaran salah satu maksim prinsip kerja sama yaitu maksim kualitas. Pada tuturan (3) yang mengatakan “谁 是梁山伯? 不认识! ” merupakan tuturan yang tidak benar atau berbohong. Karena sangat tidak benar, teman tersebut tidak mengenal Liang Shan Bo yang merupakan temannya. Sangat tidak mungkin jika dia tidak mengenalnya. Seharusnya teman Liang Shan Bo mengatakan, “我 不知道他在哪儿?“” yang bermakna Aku tidak tahu dia d imana jika memang benar-benar teman tersebut tidak tahu. Dengan demikian dapat disampaikan bahwa tuturan alernatif tersebut merupakan tuturan yang benar dan tidak melanggar maksim kualitas

Pada pertuturan tersebut, ternyata teman Liang Shan Bo (4) telah melakukan pelanggaran salah satu maksim prinsip kerja sama yaitu maksim kualitas. Pada tuturan (4) yang dilakukan oleh teman Liang Shan Bo yaitu “谁是梁山伯? 不认识! ” memiliki maksud bahwa dia merasa jengkel kepada Liang Shan Bo. Karena itu, tuturan (4) yang melanggar maksim kualitas dalam prinsip kerjasama memiliki fungsi ekspresif yaitu mengungkapkan kejengkelannya kepada Liang Shan Bo.

\section{Pelanggaran Maksim Relevan dan Fungsinya}

Data berikut ini berkonteks. Zhu Ying Tai diminta untuk menunjukkan hasil hafalan ujiannya kepada ayah dan ibunya. Akan tetapi, dia tidak hafal sehingga pelayannya memberikan contekkan melalui alas sepatunya yang sudah dia tulisi dengan ukuran kecil.

(5) Ibu Ying Tai：一都吟不出来呀?

Satu kalimat pun tidak keluar?

(6) Zhu Ying Tai : 题字太小了。

Tulisannya sangat kecil

(7) Ibu Ying Tai : 什么? 
Apa?

Pada pertuturan tersebut dapat diketahui bahwa Zhu Ying Tai (2) telah melanggar salah satu maksim prinsip kerja sama yaitu maksim relevan atau hubungan. Zhu Ying Tai (6) memberikan jawaban atas pertanyaan dari ibunya (5) dengan menuturkan “题字太小了”. Jawaban yang diberikan tersebut jelas tidak ada hubungannya dengan pertanyaan yang diberikan padanaya. Seandainya tuturan Zhu Ying Tai (2) menjawab “我不会 “ yang artinya Aku tidak bisa tentu jawaban tersebut sesuai dengan maksud tuturan Ibu Ying Tai (5) dan tidak melanggar maksim relevansi.

Pada pertuturan tersebut dapat diketahui bahwa Zhu Ying Tai (2) telah melanggar salah satu maksim prinsip kerjasama yaitu maksim relevan atau hubungan. Berdasarkan tuturan dari Zhu Ying Tai (2) yaitu “题字太小了” yang bermaksud mengeluh karena contekan yang dia lihat pada alas kaki pelayannya sangat kecil tulisannya. Karena itu, secara tidak sadar dia mengatakan, “题字太小了”. Tuturan yang melanggar maksim relevan atau hubungan memiliki fungsi asertif yaitu mengeluh

\section{Pelanggaran Maksim Cara dan Fungsinya}

Data berkonteks salah satu guru Zhu Ying Tai ingin memakaikan baju kepadanya. Akan tetapi baju dalam wanita yang ia kenakan rusak. Karena itu, Zhu Ying Tai berusaha menutupi agar identitasnya yang sebenarnya perempuan tidak diketahui oleh gurunya. Gurunya yang merasa aneh saat mencoba memakaikan baju kepada Zhu Ying Tai. Karena Zhu Ying Tai bergerak membuat baju dalamnya jatuh dan ketahuan oleh gurunya.

(8) Guru：还想蒙我呢? 我早看穿你是女孩儿。你想学你娘亲女扮男装来这捚 吟宕, 是不是?

Kamu ingin menipuku? Sejak awal aku tahu kamu adalah perempuan. Ibumu menyuruhmu sekolah dengan mendandani anak perempuan seperti laki-laki, benar bukan?

(9) Zhu Ying Tai : 英台向娘亲立了三多是。第一，不可以向人透我是...... Ada tiga peringatan ibu untuk Ying Tai. Pertama, orang lain tidak boleh tahu kalau aku adalah...

(LZ.ZYT.4.00 : $19: 20-00: 19: 35$ ) 
Pertuturan tersebut menunjukkan bahwa tuturan (9) telah melanggar maksim cara. Zhu Ying Tai (9) memberikan jawaban atas pertanyaan gurunya (8) dengan menuturkan, “英台向 娘亲立了三多是。第一, 不可以向人透我是.” Tuturan tersebut terlalu panjang dan berteletele. Padahal, gurunya hanya meminta jawaban benar atau tidak benar dari Zhu Ying Tai. Seandainya tuturan Zhu Ying Tai (9) berbunyi, “是，老师对的 “ yang artinya Iya, Guru benar sudah cukup untuk menjawab pertanyaan pada tuturan (8) tanpa harus membuat pernyataan yang panjang dan bertele-tele. Dengan jawaban tersebut dapat ditegaskan bahwa tuturan tersebut tidak sampai melanggar maksim cara.

Pelanggaran maksim cara yang dilakukan oleh Zhu Ying Tai (9) bermaksud ingin menunjukkan bahwa dia menyamar menjadi laki-laki karena permintaan dari ibunya agar dia bisa bersekolah. Tuturan (9) yang melanggar maksim cara dalam prinsip kerjasama memiliki fungsi asertif yaitu menunjukkan alasan.

\section{Simpulan}

Berdasarkan hasil analisis yang telah disajikan, dapat ditarik simpulan bahwa pelanggaran maksim-maksim prinsip kerja sama pada film 梁祝（Liang Zhu） atau Sampek Engtai sebagai berikut.

1. Bentuk pelanggaran maksim-maksim prinsip kerja sama berupa pelanggaran maksim kuantitas, pelanggaran maksim kualitas, pelanggaran maksim relevan, dan pelanggaran maksim cara. Terdapat akibat yang ditimbulkan terhadap keempat maksim dalam pertuturan tersebut. Tuturan yang melanggar maksim kuantitas mengakibatkan tidak informatifnya sebuah tuturan karena informasi yang diberikan terlalu berlebihan. Pelanggaran maksim kualitas dapat mengakibatkan lawan tutur salah menangkap informasi karena informasi yang disampaikan penutur tidak meyakinkan atau tidak benar. Kemudian, pelanggaran pada pelanggaran maksim relevan dapat menimbulkan ketidaksambungan pertuturan antara pihak penutur dan petutur. Terakhir, pelanggaran maksim cara dapat mengakibatkan salah paham dan kebingungan pada pihak penutur dan petutur karena ketidakjelasan makna tuturan.

2. Fungsi pelanggaran maksim-maksim prinsip kerjasama yaitu fungsi asertif dan fungsi ekspresif. Pelannggaran terhadap maksim-maksim tersebut berfungsi asertif memiliki maksud untuk menunjukkan, menjelaskan alasan. Selain itu, pelanggaran pada fungsi ekspresif yaitu berfungsi untuk menunjukkan perasaan jengkel dan keluhan.

\section{Daftar Pustaka}


Vol.1, No.2, Oktober 2017, PP.57-63

Leech, Geoffrey. 1993. Prinsip-Prinsip Pragmatik. Jakarta:Universitas Indonesia Press.

Tarigan, Henry Guntur.1993.Pengajaran Wacana. Bandung: Angkasa.

黄伯荣,廖序东. 2008. Xiandai Hanyu 现代汉语 (上册). 北京:高等教育出版社.

\section{Data Penulis}

Nama

Jurusan

Perguruan Tinggi

HP

Email
: Galih Wibisono, B.A., M.Ed.

: Jurusan Bahasa dan Sastra Mandarin

: Universitas Negeri Surabaya

: +628573285290

:galih_li@yahoo.com 